\title{
Evaluation of freeze-drying conditions on the process kinetics and physicochemical properties of purple shallot
}

\author{
1,*Thuy, N.M., ${ }^{1}$ Tuyen, N.T.M., ${ }^{2}$ Thanh, N.V. and ${ }^{1}$ Tai, N.V. \\ ${ }^{1}$ Department of Food Technology, College of Agriculture, Can Tho University, 900000, Can Tho, Vietnam \\ ${ }^{2}$ Biotechnology Research and Development Institute, Can Tho University, 900000, Can Tho, Vietnam
}

\author{
Article history: \\ Received: 24 May 2020 \\ Received in revised form: 5 \\ June 2020 \\ Accepted: 6 June 2020 \\ Available Online: 7 June \\ 2020
}

Keywords:

Freeze-drying,

Purple shallot,

Modelling,

Physical properties,

Bioactive compounds

DOI:

https://doi.org/10.26656/fr.2017.4(5).246

\begin{abstract}
Purple shallot is an important vegetable crop in Vietnam and throughout the world. Its storage is difficult hence, it is dehydrated for value addition. Freeze drying is one of the options for dehydration of purple shallot. There are two main stages (freezing and drying) in the complete freeze-drying process after sample pretreatment. In this study, the sample was frozen at different temperatures and times $\left(-20\right.$ to $-60^{\circ} \mathrm{C}$ and 5 to $9 \mathrm{hrs}$, respectively). Controlling the selected temperature (from the second stage) and pressure $0.001 \mathrm{mbar}$, eight thin layer drying models were fitted to the experimental moisture content. The physical and chemical properties and antioxidant capacity of freeze-dried purple shallot were evaluated. The obtained results showed that the TPC values and DPPH\% almost increased as the freezing time increased at the same freezing temperature. The best drying conditions were found at a freezing time of $7 \mathrm{hrs}$, freezing temperature of $-60^{\circ} \mathrm{C}$, a pressure of $0.001 \mathrm{mbar}$, and a lyophilization time of $12 \mathrm{hrs}$. Under these conditions, the moisture content, TPC and DPPH\% of the final product were $1.56 \%, 16.95 \mathrm{mg} \mathrm{GAE} / \mathrm{g}$ and $65.67 \%$, respectively. Among the models proposed, Page's model gave a better fit for the freeze-drying condition used. In freeze-drying, effective moisture diffusivity was estimated to be $5.68 \times 10^{-7} \mathrm{~m}^{2} / \mathrm{s}$ within the conditions studied.
\end{abstract}

\section{Introduction}

The purple shallot is cultivated in the Mekong delta of Vietnam particularly in high quantity in Vinh Chau town (Soc Trang province). The purple shallot grown in this region is highly valued by domestic and international consumers thanks to its beautiful colour (purple or faint red), big size and weight while the number of bulbs is low, and thus the bulbs are large and more convenient for cooking. Purple shallot is an excellent source of polyphenols (Thuy et al., 2020). Consumption is believed to benefit health due to their bioactive compounds exhibiting potential anti-inflammatory, anticholesterol, anticancer and antioxidant properties (Hashmi et al., 2015). However, shallot can be subject to infection by decay organisms and is sensitive to bruising and mechanical damage after harvesting. Once the shallot is infected, there is nothing that can be done to stop the decay. Although the quality of shallot is very high and the cost of raw materials is still very low, the shallot is only used as a seasoning or pickled product, not many convenient products are processed from this source. The increase in the consumption of foods that require less time to prepare has received recent attention.
Moreover, diversifying products from purple shallot to find a sustainable output and raise income for growers is the direction of Soc Trang province.

Drying is the most common food preservation process which increases shelf-life of dried products (Raponi et al., 2017). Hot-air drying is the conventional drying method but provides drastic reduction of quality of dried products (Ratti, 2001). In the traditional drying processes, water removal is achieved by evaporation at relatively high temperatures, resulted in degradation of some nutrients, colour and flavour of food. Conventional cooking of vegetables generally reduces total phenolic content and antioxidant activity (Al-Juhaimi et al., 2018). The contents of antioxidant compounds such as phenolics and their biological activities in foods may be affected by certain thermal techniques (Parmar et al., 2016). Anthocyanins are very unstable at high temperatures and oxygen and the storage duration greatly destabilizes these compounds. An alternative technique can be used is freeze-drying with three main stages of operation where each step is important for the final product (Raponi et al., 2017). Freeze-drying of food materials is one of the modern techniques of water 
removal and to produce the highest quality of the final products which proved the best methods to preserve flavour, colour and nutritional compounds due to the absence of water, low pressure and temperature (Raponi et al., 2017). Freeze-drying is also proposed for the stabilization of natural anthocyanin pigments (Cortez et al., 2017), proved to protect the primary structure and the shape of the products with minimal volume reduction. Besides, the lower temperatures in the process allow maximal nutrient and bioactive compound retention. Freeze-dried purple shallot will be used in a wide range of food products such as instant soups, instant noodles and snack food. However, limited information on the effects of freeze-drying conditions on the Vietnamese shallot's quality is available. The effect of freeze-drying (freezing rate and time) on the quality of freeze-dried shallot is discussed. Describing dehydration kinetics is important in the design and optimization of this process (Planinic et al., 2005). From a processing and engineering point of view, it is interesting to know how fast the evaporation of water can be accomplished and how the drying time under given conditions can be predicted. Thin-layer drying equations are important in the mathematical modelling of drying. They are practical and provide sufficiently good results (Erbay and Icier, 2009). The objective of this study is to provide a brief review of some advances in modelling moisture changes of purple shallot during freeze-drying. Approaches to monitoring and modelling of moisture and relation to microstructural changes are also mentioned.

\section{Materials and methods}

\subsection{Sample preparation}

The fresh and matured purple shallots were harvested from Vinh Chau town, Soc Trang province, Vietnam. The outer skin of shallot bulbs was removed by stainless steel knife. The peeled purple shallot bulbs were thoroughly washed with tap water to remove contaminants. Then they were dried in the drier (55$60^{\circ} \mathrm{C}$ ) for one hour to remove the surface water. Before treatment, the purple shallot bulbs were cut manually into halves by using a stainless steel knife.

\subsection{Freeze drying procedure}

Experiments were performed using three different freezing equipment, where: $(i)$ in the household freezer (Sharp, Korea) (freezing rate: $0.5^{\circ} \mathrm{C} / \mathrm{min}$, freezing down to $-20^{\circ} \mathrm{C}$ ), (ii) in the low-temperature freezer (Plus + series 15 , USA), (freezing rate: $2^{\circ} \mathrm{C} / \mathrm{min}$, to $-40^{\circ} \mathrm{C}$ ), (iii) in ultra-low temperature freezer (HC VIP-99338J, USA) (freezing rate: $3^{\circ} \mathrm{C} / \mathrm{min}$, to $-60^{\circ} \mathrm{C}$ ). Three freezing rates were used to freeze purple shallot at a different time (from 5 to $9 \mathrm{hrs}$ ). Then, the frozen samples were freeze- dried at $-80^{\circ} \mathrm{C}$ condenser temperature, the vacuum was 0.001 mbar. The quality of freeze-dried purple shallot was analysed.

\subsection{Mathematical modelling of drying data}

Controlling the selected freezing temperature and pressure 0.001 mbar, the moisture loss was determined by weighing the samples using a digital balance with 0.01 precision. The moisture ratio (MR) of purple shallots during freeze-drying was calculated using the following Equation 1.

$$
M R=\frac{M_{t}-M_{e}}{M_{o}-M_{e}}
$$

Where $\mathrm{M}_{\mathrm{t}}, \mathrm{M}_{\mathrm{o}}$ and $\mathrm{M}_{\mathrm{e}}$ are moisture content $(\mathrm{kg}$ water $/ \mathrm{kg}$ dry matter) at each measurement time, initial moisture content, and equilibrium moisture content, respectively. The relative moisture of the drying air (Equation 1), which varied continuously during the drying experiments, is simplified into Equation 2 (Akpinar et al., 2003):

$$
M R=\frac{M_{t}-M_{e}}{M_{0}-M_{e}} \quad \text { to } \quad M R=\frac{M_{t}}{M_{0}}
$$

Eight well-known thin layer drying models were fitted to the experimental data and are given in Table 1.

A nonlinear regression analysis was used to evaluate the parameters of the selected model using the statistical software Statgraphics Centurion XV.I (USA). The proper fit was determined using the coefficient of determination $\left(\mathrm{R}^{2}\right)$, the root mean square error (RMSE), and the reduced Chi-square $\left(\chi^{2}\right)$ that are described as Equation 3, 4 and 5, respectively.

$$
\begin{aligned}
& R^{2}=\frac{N \sum_{i=1}^{N} M R_{\text {pre } i} M R_{\text {exp }, i}-\sum_{i=1}^{N} M R_{\text {pre }, i} \sum_{i=1}^{N} M R_{\text {exp }, i}}{\sqrt{\left(N \sum_{i=1}^{N} M R_{\text {pre } i}^{2}-\left(\sum_{i=1}^{N} M R_{\text {pre }, i}\right)^{2}\right)\left(\sum_{i=1}^{N} M R_{\text {exp }, i}^{2}-\left(\sum_{i=1}^{N} M R_{\text {exp }, i}\right)^{2}\right)}} \\
& R M S E=\left[\frac{1}{N} \sum_{i=1}^{N}\left(M R_{\text {pre }, i}-M R_{\text {exp }, i}\right)^{2}\right]^{1 / 2} \\
& \chi^{2}=\frac{\sum_{i=1}^{N}\left(M R_{\text {pre }, i}-M R_{\text {exp }, i}\right)^{2}}{N-n}
\end{aligned}
$$

Where $\mathrm{MR}_{\text {exp,I }}$ and $\mathrm{MR}_{\text {pre, } \mathrm{i}}$ is the experimental and predicted moisture ratio at observation $i$; $\mathrm{N}$ is the number of the experimental data points, and $n$ is the number of constants in the model. For determination of the effective moisture diffusivity $\left(\mathrm{D}_{\text {eff }}\right)$ of the freeze-dried samples; Fick's diffusion model was used in Equation 6.

$M R=\frac{8}{\pi^{2}} \sum_{n=0}^{\infty} \frac{1}{(2 n+1)^{2}} \exp \left[-(2 n+1)^{2} \pi^{2} \frac{D_{\text {eff }}}{4 L^{2}} t\right]$

Where $t$ is the time (s), $D_{\text {eff }}$ is the effective diffusivity $\left(\mathrm{m}^{2} / \mathrm{s}\right)$ and $\mathrm{L}$ is the thickness of samples $(\mathrm{m})$. For long drying times (MR $<0.6$ ), a limiting case Equation 7 is obtained and expressed in a logarithmic form (Bennamoun et al., 2013). 
Table 1. Selected thin layer drying models for describing the drying characteristic of purple shallot

\begin{tabular}{llll}
\hline \multicolumn{1}{c}{ Models } & \multicolumn{1}{c}{ Equation } & \multicolumn{1}{c}{ Models } & \multicolumn{1}{c}{ Equation } \\
\hline Lewis & $M R=e^{(-k t)}$ & Logarithmic & $M R=a e^{(-k t)}+c$ \\
Henderson and Pabis & $M R=a e^{(-k t)}$ & Midilli & $M R=a e^{(-k t)}+b t$ \\
Page & $M R=e^{\left(-k(t)^{n}\right)}$ & Modified Midilli & $M R=\exp ^{(-k t)}+b t$ \\
Wang and Smith & $M R=1+a t+b t^{2}$ & Two-term & $M R=a e^{\left(-k_{1} t\right)}+b e^{\left(-k_{2} t\right)}$ \\
\hline
\end{tabular}

Source: Erbay and Icier (2010)

$$
\ln M R=\ln \left(\frac{8}{\pi^{2}}\right)-\left(\frac{\pi^{2} D_{\text {eff }}}{4 L^{2}}\right) t
$$

The effective diffusivity is typically calculated by plotting experimental moisture ratio in logarithmic form versus drying time. From Equation 7, a plot of $\ln M R$ versus drying time gives a straight line with the slope given in Equation 8.

$$
\text { Slope }=\frac{\pi^{2} D_{\text {eff }}}{4 L^{2}}
$$

\subsection{Physical properties analysis}

\subsubsection{Determination of moisture content}

The moisture content analysis was carried out based on the Association of Official Analytical Chemists method (AOAC, 2005).

\subsubsection{Scanning Electron Microscopy (SEM)}

Dried purple shallot was cut using a razor blade and the sample was mounted onto brass stubs using doublesided carbon conductive adhesive tape. A gold coating (0.5 nanometers thick) was then applied under 8-9 pascal vacuum. Bulk samples were examined at $15 \mathrm{kV}$, the sample distance to the $7 \mathrm{~cm}$ ejection glass, $230 \mathrm{x}$ magnification using a JEOL model J550 scanning electron microscope (Japan).

\subsection{Determination of bioactive compounds and antioxidant activity}

Total phenolic compounds (TPC) were determined using a modified Folin-Ciocalteau colourimetric method (Wolfe et al., 2003). Briefly, $0.5 \mathrm{~mL}$ of diluted extract was mixed with $0.5 \mathrm{~mL}$ of Folin Ciocalteu's reagent. After 3 mins, $10 \mathrm{~mL}$ of saturated $7.0 \% \mathrm{Na}_{2} \mathrm{CO}_{3}$ was added to the mixture and it was incubated in the dark for $1 \mathrm{hr}$. The absorbance of blue-colored complex solution was then read at $725 \mathrm{~nm}$. Different concentrations of gallic acid $(0.02-0.10 \mathrm{mg} / \mathrm{mL})$ were used to construct a calibration curve. The results were expressed as miligram of gallic acid equivalent per hundred gram of fresh weight (mg GAE/100 g FW).

Free radical scavenging activity (DPPH\%) of the sample was carried out according to the method described by Liyana and Shahidi (2005). Briefly, $3.5 \mathrm{~mL}$ of methanolic solution ( $25 \mu \mathrm{g} / \mathrm{mL}$ DPPH) was added to
$0.5 \mathrm{~mL}$ extract at different concentrations. The reaction mixture was then vortexed and kept at room temperature for 30 mins. The absorbance was then measured at 515 $\mathrm{nm}$. The results were expressed in percent inhibition at 5 $\mathrm{mg} / \mathrm{mL}$. The antioxidant activity was calculated as Equation 9.

DPPH $(\%)=\left[\left(\Delta \mathrm{A}_{515 \mathrm{~nm}}\right.\right.$ of control- $-\Delta \mathrm{A}_{515 \mathrm{~nm}}$ of sample $) / \Delta \mathrm{A}_{515 \mathrm{~nm}}$ of control] $\times 100 \%$

\section{Results and discussion}

3.1 Effect of frozen conditions on the quality of freezedried purple shallot

The ice crystal formation has a pronounced effect on the quality characteristics of the final dried product. The morphology of the ice crystals formed has an influential role on the interconnectivity and stability of the porous network of the final dried product as well as the efficiency of the subsequent drying steps (Ratti, 2001; Hottot et al., 2007; Harnkarnsujarit et al., 2016). The moisture content of freeze-dried purple shallot at various freezing conditions can be observed in Table 2. As can be seen in this table, with different freezing temperatures, the obtained moisture content of freezedried samples ranged from 3.27 to $1.85 \%, 2.51$ to $1.76 \%$ and 2.36 to $1.33 \%$ for $-20,-40$ and $-60^{\circ} \mathrm{C}$, respectively. However, at $-60^{\circ} \mathrm{C}$ for $7-9 \mathrm{hrs}$, the moisture of the final product was not significant difference (from 1.33 to $1.39 \%)$. The important feature to consider is moisture content of all dried samples were below 5\%, which indicated that the growth of moulds, bacteria, and yeast is not promoted, and enzymatic reactions are not likely to occur.

Table 2. Effect of freezing conditions on the moisture content of freeze-dried purple shallot

\begin{tabular}{cccc}
\hline Freezing temperature & \multicolumn{3}{c}{ Freezing time (hrs) } \\
\cline { 2 - 4 }$\left({ }^{\circ} \mathrm{C}\right)$ & 5 & 7 & 9 \\
\hline-20 & $3.27 \pm 0.05$ & $2.41 \pm 0.06$ & $1.85 \pm 0.10$ \\
-40 & $2.51 \pm 0.05$ & $1.94 \pm 0.04$ & $1.76 \pm 0.02$ \\
-60 & $2.36 \pm 0.06$ & $1.39 \pm 0.16$ & $1.33 \pm 0.22$ \\
\hline
\end{tabular}

Values are expressed as mean $\pm \mathrm{SD}$

Polyphenols have been widely studied due to their health-promoting properties through their antioxidant activity. Results of TPCs of freeze-dried purple shallots are shown in Table 3. From the obtained results, it can be 
concluded that the TPC values almost increased as the freezing time increased at the same freezing temperature $(14.47-16.42, \quad 16.45-17.55, \quad 16.73-17.69 \mathrm{mg}$ GAE/g corresponding to $\left.-20,-40,-60^{\circ} \mathrm{C}\right)$. Tomsone and Kruma (2014) reported that there was an increase in antioxidant compounds in plant materials after freezing. Leong and Oey (2012) also found that antioxidant compounds that exist as binding in plant cell membranes could be released during blanching or freezing, thereby increasing these compounds. Many studies were able to correlate freezing parameters with physicochemical properties and quality of freeze-dried foods (Hottot et al., 2004; Voda et al., 2012; Ceballos et al., 2012; Serna-Cock et al., 2015; Nowak et al., 2016). It has been reported that the TPC content of freeze-dried fruit powders increased with increasing freezing rate due to high mass transfer resistance in small pores (Ceballos et al., 2012).

Table 3. Effect of freezing conditions on TPC values $(\mathrm{mg}$ $\mathrm{GAE} / \mathrm{g}$ ) of freeze-dried purple shallot

\begin{tabular}{cccc}
\hline Freezing & \multicolumn{3}{c}{ Freezing time (hrs) } \\
\cline { 2 - 4 } temperature $\left({ }^{\circ} \mathrm{C}\right)$ & 5 & 7 & 9 \\
\hline-20 & $14.49 \pm 0.05$ & $15.48 \pm 0.18$ & $16.42 \pm 0.13$ \\
-40 & $16.45 \pm 0.01$ & $17.25 \pm 0.20$ & $17.55 \pm 0.17$ \\
-60 & $16.73 \pm 0.57$ & $17.00 \pm 0.56$ & $17.69 \pm 0.29$ \\
\hline
\end{tabular}

Values are expressed as mean $\pm \mathrm{SD}$

Table 4. Effect of freezing conditions on DPPH (\%) values of freeze-dried purple shallot

\begin{tabular}{cccc}
\hline Freezing & \multicolumn{3}{c}{ Freezing time (hrs) } \\
\cline { 2 - 4 } temperature $\left({ }^{\circ} \mathrm{C}\right)$ & 5 & 7 & 9 \\
\hline-20 & $60.85 \pm 0.47$ & $62.00 \pm 0.83$ & $63.46 \pm 0.94$ \\
-40 & $61.69 \pm 0.83$ & $62.25 \pm 1.02$ & $63.53 \pm 0.94$ \\
-60 & $61.99 \pm 1.69$ & $65.07 \pm 0.54$ & $67.70 \pm 0.47$ \\
\hline
\end{tabular}

Values are expressed as mean $\pm \mathrm{SD}$

The scavenging of free radical by antioxidants is achieved by donating hydrogen to form the stable DPPH$\mathrm{H}$ molecule. The DPPH radical-scavenging activities of the freeze-dried sample at a different freezing time and temperature almost increased (Table 4). It was almost similar to the changes of polyphenol compounds because these compounds play a key role in the antioxidant activity. Duy and Vuong (2013) showed the relationship between these compounds and antioxidant activity. Thanh and Thuy (2016) also reported that the increase of antioxidant compounds and antioxidant activity of garlic after the low-temperature treatment.

\subsection{Microstructural properties of freeze-dried matrices}

The SEM images showed the interconnected solid networks and embedded pores previously occupied by ice crystals during pre-freezing and vacated as a result of ice sublimation. Figure 1 shows the SEM micrographs of the freeze-dried samples obtained from three different freezing temperatures. It could be appreciated the qualitative differences in pore size and homogeneity of the three freeze-dried purple shallots. The lower freezing rate generated higher size pores and a more ordered structure. Freezing at $-20^{\circ} \mathrm{C}$ produced the largest pore size; whereas the smallest pores were seen under the freezing condition at $-60^{\circ} \mathrm{C}$. Ice sublimation left the pores embedded in the matrices which determined ice nucleation and growth during freezing and freeze-drying. The lower freezing temperatures and hence higher freezing rates increased the rate of ice nucleation concurrently with limited ice growth during freezing. The nucleation rate defines the number of ice crystals; while the rate of heat and protein diffusion away from the point of nucleation defines the ice crystal size (O'Brien et al., 2004); therefore, large numbers of small ice crystals were formed during fast freezing which contributed to the smaller pore sizes after ice sublimation.

\subsection{Drying characteristic and evaluation of the models}

The drying behaviour of the purple shallot during freeze-drying was determined from the mass loss in the samples of known initial moisture content $[85.72 \pm 0.47 \%$ (wet basis)]. The moisture loss was recorded at one-hour intervals during freeze-drying until a constant weight was achieved. As expected, the major part of the moisture was removed in the early stages of drying and it gradually decreased in later stages. The moisture content was converted to moisture ratio and fitted to the eight thin layer models. The summary of the models' parameters $\left(\mathrm{k}, \mathrm{n}, \mathrm{a}, \mathrm{b}, \mathrm{c}, \mathrm{k}_{1}\right.$ and $\left.\mathrm{k}_{2}\right)$ of the eight thin layer drying models that were used for expressing drying characteristics and the statistical evaluation of the models using three different criteria $\left(\mathrm{R}^{2}, \mathrm{RMSE}\right.$ and $\left.\chi^{2}\right)$

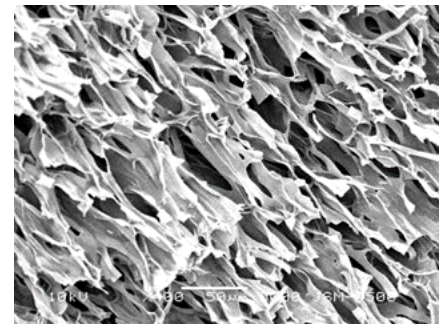

(a)

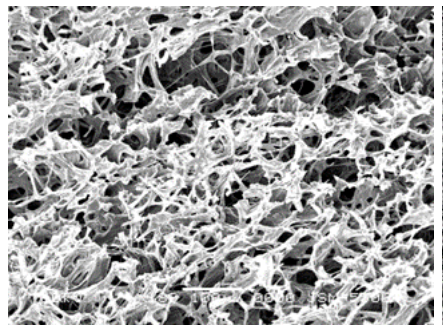

(b)

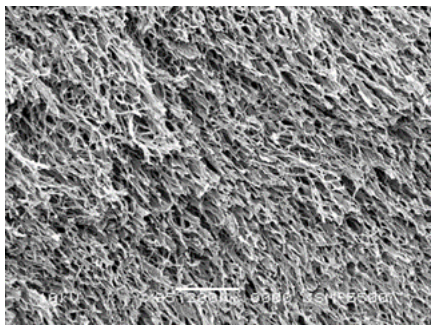

(c)

Figure 1. SEM photographs of freeze-dried purple shallot under various freezing conditions (a. $-20^{\circ} \mathrm{C}$; b. $-40^{\circ} \mathrm{C}$; c. $\left.-60^{\circ} \mathrm{C}\right)$ for 7 hrs before freeze-drying 
Table 5. The model equations and statistical results $\left(\mathrm{R}^{2}, \mathrm{RMSE}\right.$ and $\left.\chi^{2}\right)$

\begin{tabular}{|c|c|c|c|c|}
\hline Models & Equation & $\mathrm{R}^{2}$ & RMSE & $\chi^{2}$ \\
\hline Lewis & $M R=e^{(-0.544 t)}$ & 99.00 & 0.03 & 0.0010 \\
\hline Henderson and Pabis & $M R=1.025 e^{(-0.556 t)}$ & 99.07 & 0.03 & 0.0011 \\
\hline Page & $M R=e^{\left(-0.45 t^{1.251}\right)}$ & 99.49 & 0.02 & 0.0006 \\
\hline Wang and Smith & $M R=1-0.271 t+0.017 t^{2}$ & 85.26 & 0.12 & 0.0176 \\
\hline Logarithmic & $M R=1.019 e^{(-0.57 t)}+0.008$ & 99.10 & 0.03 & 0.0013 \\
\hline Midilli & $M R=1.028 e^{(-0.566 t)}+0.001 t$ & 99.13 & 0.03 & 0.0013 \\
\hline Modified Midilli & $M R=\exp ^{(-0.552 t)}+0.001 t$ & 99.06 & 0.0 & 0.0011 \\
\hline Two-term & $M R=1.026 e^{(-0.562 t)}+0.0009 e^{(-0.258 t)}$ & 99.14 & 0.032 & 0.0015 \\
\hline
\end{tabular}

are presented in Table 5. It was observed that the calculated $\mathrm{R}^{2}>0.85$ for all of the models. The coefficient of correlation $\left(\mathrm{R}^{2}\right)$ was one of the primary criteria for selecting the best model to define the freeze-drying behaviour of the purple shallot. In different studies, thinlayer drying models in which the $\mathrm{R}^{2}$ value is highest and the RMSE, and $\chi^{2}$ values are the smallest were chosen to be the most suitable models (Yaldiz et al., 2001; Togrul and Pehivan, 2002; Akpinar et al., 2003; Ertekin and Yaldiz, 2004). As can be seen in Table 5, the highest $\mathrm{R}^{2}$ and the lowest $\chi^{2}$ and RMSE were obtained from the Page model. The Page model was also found to be suitable for the convective and microwave drying of white onion (3 mm) (Demiray et al., 2017).

The drying curves obtained by fitting the drying models to the experimental data and model equations are given in Figure 2 and it was observed that only a falling rate period took place during freeze-drying. As seen, the established model gave a good agreement between the predicted and the experimental moisture ratio values. The constants, coefficients, and statistical results of the Page model are given in Equation 10, 11 and 12, respectively.

$$
\begin{aligned}
M R & =e^{\left(-k(t)^{n}\right)} \\
M R & =e^{\left(-0.45 t^{1.251}\right)} \\
\mathrm{R}^{2} & =99.48, \text { RSME }=0.02, \chi^{2}=0.006
\end{aligned}
$$

The effective moisture diffusivity $\left(\mathrm{D}_{\text {eff }}\right)$ of the freeze -dried purple shallot was calculated using the Fick's diffusion model as $5.68 \times 10^{-7} \mathrm{~m}^{2} / \mathrm{s}$. Demiray et al. (2017) reported that the effective moisture diffusivity of onion slices which was dried under convective drying (50$70^{\circ} \mathrm{C}$ ) estimated between $3.49 \times 10^{-8}$ and $9.44 \times 10^{-8} \mathrm{~m}^{2} / \mathrm{s}$. This study also reported that at increasing microwave power values (328-557 W), the effective moisture diffusivity values ranged from $2.59 \times 10^{-7}$ and $5.08 \times 10^{-8}$ $\mathrm{m}^{2} / \mathrm{s}$. Also, Erbay and Icier (2010) reported that the effective moisture diffusivity values in foods were in the range of $10^{-12}$ to $10^{-6} \mathrm{~m}^{2} / \mathrm{s}$, were similar to this study.

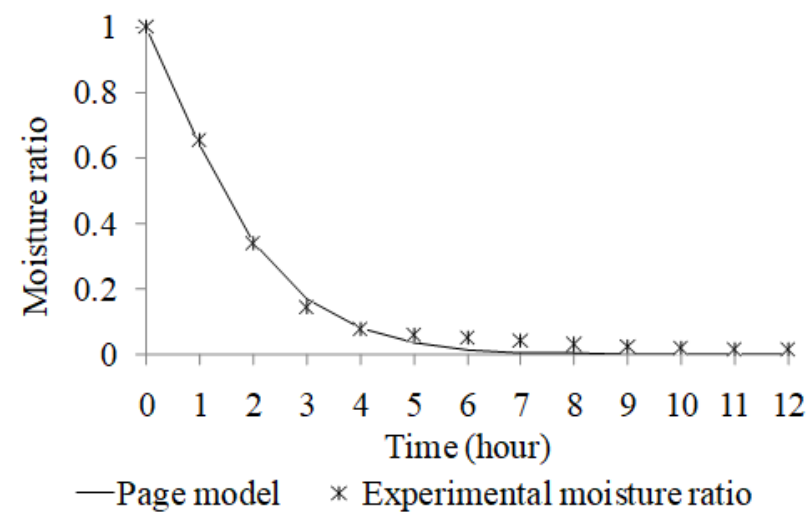

Figure 2. The moisture ratio vs time for Page model fitting own experimental data for freeze-drying $\left(80^{\circ} \mathrm{C}, 0.001 \mathrm{mbar}\right)$ of purple shallot

\section{Conclusion}

The suitable conditions for dried purple shallots freeze-drying are a freezing time of $7 \mathrm{hrs}$, a freezing temperature of $-60^{\circ} \mathrm{C}$, a pressure of $0.001 \mathrm{mbar}$, and a lyophilization time of $12 \mathrm{~h}$. Under these conditions, the freeze-dried shallot product had low moisture content $(1.56 \%)$ and good structure. Among the eight thin layerdrying models, Page model $\left(\mathrm{R}^{2}=99.48, \mathrm{RSME}=0.02\right.$, $\left.\chi^{2}=0.006\right)$ was chosen to estimate the moisture ratio of purple shallots during the freeze-drying process with great accuracy. The effective moisture diffusivity $\left(\mathrm{D}_{\text {eff }}\right)$ of freeze-dried purple shallot was found to be as $5.68 \times$ $10^{-7} \mathrm{~m}^{2} / \mathrm{s}$. The results of the present study revealed that freeze-drying can be explored as a viable method for processing purple shallot with retaining the highest content of their naturally inherent bioactive compounds. The obtained results also show that freeze-dried purple shallots are good sources of antioxidants. Further research on the quality of this material in small scale processing and evaluation of their quality is recommended. 


\section{Acknowledgements}

We are thankful to the Department of Science and Technology of Soc Trang Province for their financial support and all cordial assistance.

\section{References}

Akpinar, E., Midilli, A. and Bicer, Y. (2003). Singlelayer drying behaviour of potato slices in a convective cyclone dryer and mathematical modelling. Energy Conversion and Management, 44 (10), 1689-1705. https://doi.org/10.1016/S0196-8904 (02)00171-1

Al-Juhaimi, F., Ghafoor, K., Özcan, M.M., Jahurul, M.H.A., Babiker, E.E., Jinap, S. and Zaidul, I.S.M. (2018). Effect of various food processing and handling methods on the preservation of natural antioxidants in fruits and vegetables. Journal of Food Science and Technology, 55(10), 3872-3880. https://doi.org/10.1007/s13197-018-3370-0

AOAC (Association of Official Analytical Chemists). (2005). Official methods of analysis of the Association of Analytical Chemists International. Arlington, USA: AOAC.

Bennamoun, L., Kahlerras, L., Michel, F., Courard, L., Salmon, T., Fraikin, L. and Léonard, A. (2013). Determination of moisture diffusivity during drying of mortar cement: experimental and modelling study. International Journal of Energy Engineering, 3(1), 1 $-6$.

Ceballos, A.M., Giraldo, G.I. and Orrego, C.E. (2012). Effect of freezing rate on quality parameters of freeze-dried soursop fruit pulp. Journal of Food Engineering, 111(2), 360-365. https:// doi.org/10.1016/j.jfoodeng.2012.02.010

Cortez, R., Luna-Vital, D.A., Margulis, D. and Gonzalez de Mejia, E. (2017). Natural pigments: stabilization methods of anthocyanins for food applications. Comprehensive Reviews in Food Science and Food Safety, 16(1), 180-198. https://doi.org/10.1111/15414337.12244

Demiray, E., Seker, A. and Tulek, Y. (2017). Drying kinetics of onion (Allium cepa L.) slices with convective and microwave drying. Heat and Mass Transfer, 53(5), 1817-1827. https://doi.org/10.1007/ s00231-016-1943-x

Duy, N.X. and Vuong, H.B. (2013). Antioxidant Activity and Polyphenoloxidase Inhibitory Activity of Edible Plants in Vietnam. Journal of Science and Development, 11(3), 364-372.

Erbay, Z. and Icier, F. (2009). A review of thin layer drying of foods: theory, modeling, and experimental results. Critical Review in Food Science and
Nutrition, 50(5), 441-464. https:// doi.org/10.1080/10408390802437063

Erbay, Z. and Icier, F. (2010). A review of thin-layer drying of foods: theory, modelling, and experimental results. Critical Reviews in Food Science and Nutrition, 50(5), 441-464. https:// doi.org/10.1080/10408390802437063

Ertekin, C. and Yaldiz, O. (2004). Drying of eggplant and selection of a suitable thin layer drying model. Journal of Food Engineering, 63(3), 349-359. https://doi.org/10.1016/j.jfoodeng.2003.08.007

Harnkarnsujarit, N., Kawai, K., Watanabe, M. and Suzuki, T. (2016). Effects of freezing on microstructure and rehydration properties of freezedried soybean curd. Journal of Food Engineering, 184, 10-20. https://doi.org/10.1016/ j.jfoodeng.2016.03.014

Hashmi M.A., Khan A., Hanif H., Farooq U. and Perveen S. (2015). Traditional Uses, Phytochemistry, and Pharmacology of Olea europaea (Olive) Evidence-Based Complementary Alternative Medicine, 2015, 541591. https:// doi.org/10.1155/2015/541591

Hottot, A., Vessot, S. and Andrieu, J. (2004). A direct characterization method of the ice morphology. Relationship between mean crystals size and primary drying times of freeze-drying processes. Drying Technology, 22(8), 2009-2021. https:// doi.org/10.1081/DRT-200032717

Hottot, A., Vessot, S. and Andrieu, J. (2007). Freezedrying of pharmaceuticals in vials: Influence of freezing protocol and sample configuration on ice morphology and freeze-dried cake texture. Chemical Engineering and Processing: Process Intensification, 46(7), 666-674. https:// doi.org/10.1016/j.cep.2006.09.003

Liyana, P.C.M. and Shahidi, F. (2005). Antioxidant activity of commercial soft and hard wheat (Triticum aestivum L.) as affected by gastric $\mathrm{pH}$ conditions. Journal of Agricultural and Food Chemistry, 53(7), 2433-2440. https://doi.org/10.1021/jf049320i

Nowak, D., Piechucka, P., Witrowa-Rajchert, D. and Wiktor, A. (2016). Impact of material structure on the course of freezing and freeze-drying and the properties of the dried substance, as exemplified by celery. Journal of Food Engineering, 180, 22-28. https://doi.org/10.1016/j.jfoodeng.2016.01.032

O'Brien, F.J., Harley, B.A., Yannas, I.V. and Gibson, L. (2004). Influence of freezing rate on pore structure in freeze-dried collagen-GAG scaffolds. Biomaterials, 25(6), 1077-1086. https://doi.org/10.1016/S01429612(03)00630-6 
Parmar, N., Singh, N., Kaur, A., Virdi, A.S. and Thakur, S. (2016). Effect of canning on colour, protein and phenolic profile of grains from kidney bean, field pea and chickpea. Food Research International, 89 (Part 1), 526-532. https://doi.org/10.1016/ j.foodres.2016.07.022

Planinic, M., Velic, D., Tomas, S., Bilic, M. and Bucic, A. (2005) Modelling of drying and rehydration of carrots using Peleg's model. European Food Research Technology, 221, 446-451

Raponi, F., Moscetti, R., Monarca, D., Colantoni, A. and Massantini, R. (2017). Monitoring and optimization of the process of drying fruits and vegetables using computer vision: a review. Sustainability, 9(11), 2009. https://doi.org/10.3390/su9112009

Ratti, C. (2001). Hot air and freeze-drying of high-value foods: a review. Journal of Food Engineering, 49(4), 311-319. https://doi.org/10.1016/S0260-8774(00) 00228-4

Serna-Cock, L., Vargas-Muñoz, D.P. and Aponte, A.A. (2015). Structural, physical, functional and nutraceutical changes of freeze-dried fruit. African Journal of Biotechnology, 14(6), 442-450. https:// doi.org/10.5897/AJB2014.14189

Togrul, İ.T. and Pehlivan, D. (2003). Modelling of drying kinetics of single apricot. Journal of Food Engineering, 58(1), 23-32. https://doi.org/10.1016/ S0260-8774(02)00329-1

Tomsone, L. and Kruma, Z. (2014). Influence of freezing and drying on the phenol content and antioxidant activity of horseradish and lovage. In 9th Baltic Conference on Food Science and Technology "Food for consumer well-being", Conference Proceedings, p. 192-197. Jelgava, Latvia.

Thanh, D.K. and Thuy, N.M. (2016). Effect of pretreatments (blanching, freezing, combine of blanching and freezing) on bioactive compounds and free radical scavenging activity of garlic. Can Tho University Journal of Science, 1, 25-32. https:// doi.org/10.22144/ctu.jsi.2016.018

Thuy, N.M., Tuyen, N.T.M, Cuong, N.P., Huyen, L.T.N, Phuong, N.P, Nguyen, L.T.T, Kim, J.H., Thu, N.T. and Tai, N.V. (2020). Identification and extraction method of quercetin from flesh and skin of shallot (Allium ascalonicum) cultivated in Soc Trang province, Vietnam. Food Research, 4(2), 358-365. https://doi.org/10.26656/fr.2017.4(2).306

Voda, A., Homan, N., Witek, M., Duijster, A., van Dalen, G., van der Sman, R. and van Duynhoven, J. (2012). The impact of freeze-drying on microstructure and rehydration properties of carrot. Food Research International, 49(2), 687-693. https://doi.org/10.1016/j.foodres.2012.08.019

Wolfe, K., Wu, X. and Liu, R.H. (2003). Antioxidant activity of apple peels. Journal of Agricultural and Food Chemistry, 51(3), 609-614. https:// doi.org/10.1021/jf020782a

Yaldiz, O., Ertekin, C. and Uzun, H.I. (2001). Mathematical modelling of thin layer solar drying of sultana grapes. Energy, 26(5), 457-465. https:// doi.org/10.1016/S0360-5442(01)00018-4 